\title{
Features of the Earth surface deformations in the Kamchatka peninsula and their relation to geoacoustic emission
}

\author{
I. A. Larionov, Y. V. Marapulets, and B. M. Shevtsov \\ Institute of Cosmophysical Research and Radio Wave Propagation (FEB RAS), Paratunka Kamchatskiy krai, Russia \\ Correspondence to: Y. V. Marapulets (marpl@ikir.ru) and I. A. Larionov (igor@ikir.ru)
}

Received: 7 July 2014 - Published in Solid Earth Discuss.: 15 August 2014

Revised: 30 October 2014 - Accepted: 11 November 2014 - Published: 10 December 2014

\begin{abstract}
The paper presents the results of investigations of deformation processes in the near-surface sedimentary rocks, which have been carried out in a seismically active region of the Kamchatka peninsula since 2007. The peculiarity of the experiments on registration of geodeformations is the application of a laser strainmeter-interferometer constructed according to the Michelson interferometer scheme. Besides rock deformations, geoacoustic emission in the frequency range from several hertz to the first tens of kilohertz is under investigation. Piezoceramic hydrophones installed in artificial water reservoirs are applied. It is shown that periods of primary rock compression and tension with a duration of up to several months are distinguished in the geodeformation process at the observation site. During the direction change in the deformations, when the geodeformation process rate grows, an increase in geoacoustic radiation is observed.
\end{abstract}

\section{Introduction}

The Kamchatka peninsula, one of the seismically active regions of the planet, is a natural test ground for investigation of seismo-tectonic processes that appear as a result of stress accumulation and relaxation in the lithosphere. It is a natural geodeformation process accompanying the movement and interaction of continental and oceanic plates. The topicality of its investigation is determined by the fact that it plays an important role in many geophysical processes that are discussed in seismology, mining and other spheres of science and engineering. Acoustic emissions are elastic oscillations occurring as a result of dislocation changes in a medium. They are often used to make diagnostics of deformations, since the characteristics of the excited radiation are directly associated with deformation process features. The phenomenon of acoustic emission is observed in a wide range of materials, structures and processes. The largestscale acoustic emission is associated with seismic waves, whereas the least-scale level is caused by dislocation movement in crystals. Between these two types of acoustic emission is a wide range of scales, from laboratory tests and natural experiments to industrial control (Pollock, 1970, 1989). The mesoscale range, corresponding to sound vibrations, has an intermediate position according to wavelength, and plays an important role in the interaction of macro and micro dislocations. Hardness of landscapes, mountain slopes, glaciers, snow covers and large technical constructions are associated with mesoscale deformation processes. An increase in regional mesoscale deformations is observed at the final stage of earthquake preparation (Agnew and Wyatt, 2003; Berardino et al., 2002; Dolgikh et al., 2007; Sasorova et al., 2008). As a result, local effects of earthquake precursors of different natures appear, including those in acoustic signals of the sound range (Dolgikh et al., 2007; Gregori et al., 2005, 2010; Kuptsov, 2005; Levin et al., 2010; Morgunov et al., 1991; Paparo et al., 2002; Sasorova et al., 2008).

During the development of acoustic methods for investigation of mesoscale deformations, the principal difficulties appear due to the significant inhomogeneity of natural media and hard propagation conditions for elastic oscillations, particularly in the frequency range of the first kilohertz. Strong distortion and weakening of a signal restrict the possibilities of remote methods and require the development of distributed measuring systems applying modern data-processing technologies that have reached the required level only during recent years. Investigation of the relation of geoacoustic emission to regional deformation disturbances 
needs the organization of long distributed observations, construction of specialized systems for data acquisition and processing, and development of models adopted to real conditions for solving inverse problems to determine the regions of deformation disturbances.

It is reasonable to carry out investigations of mesoscale deformations in seismically active regions. A seismotectonic process is constantly going on there, accompanied by stronger rock deformations; thus, stronger effects in geoacoustic emissions should be registered. It is confirmed by the results of investigations in different seismically active regions (Gregori et al., 2005, 2010; Kuptsov, 2005; Levin et al., 2010; Morgunov et al., 1991; Paparo et al., 2002; Sasorova et al., 2008), where geoacoustic emission anomalies in the frequency range of the first kilohertz, which preceded strong earthquakes, were determined. The papers (Alekseev et al., 2001; Dobrovolsky, 2000; Okada, 1985; Vodinchar et al., 2007) present the models, which show the deformation nature of the appearance of such anomalies, and the paper (Dolgikh et al., 2007) experimentally confirms the relation of the geoacoustic emission anomaly to the dynamics of geodeformation processes before an earthquake. Near-surface sedimentary rocks, characterized by low strength and high plasticity, are the most suitable for investigation of deformations. Even a small stress change there causes geoacoustic emission. It should be taken into account that changes in sedimentary rock deformations may be determined both by the dynamics of a regional seismotectonic process and the local peculiarities of a registration site. Rock plastic flows from near mountain slopes, soil seasonal freezing and defrosting; sharp changes in atmospheric pressure during cyclones may also contribute. In all these cases, anomalous behavior of geodeformation processes and geoacoustic emission responses will be registered. In the present paper, the authors did not aim at the classification of anomalies in deformations, but they tried to analyze the peculiarities of a geodeformation process registered at one measurement site within a long period of time and to determine the peculiarities of its relation to geoacoustic emission.

\section{Measurement technique}

A laser strainmeter-interferometer of an unequal-arm type, constructed according to the scheme of Michelson interferometer (Fig. 1) and developed at TOI FEB RAS (Dolgikh et al., 2007, 2012), is used to investigate deformations. The principle of operation of a laser strainmeter is that strainmeter basis change causes additional phase increment in a laser radiation wave. The measurement method is the following. Shift of interferometer mirrors, placed at the ends of basis $l$, by a $\lambda / 2$ value, results in the change in interference pattern by one band where $\lambda$ is the light wavelength on which the interferometer operates. Total relative shift will be equal to $\Delta l=N(\lambda / 2)$, where $N$ is the number of interference pat-

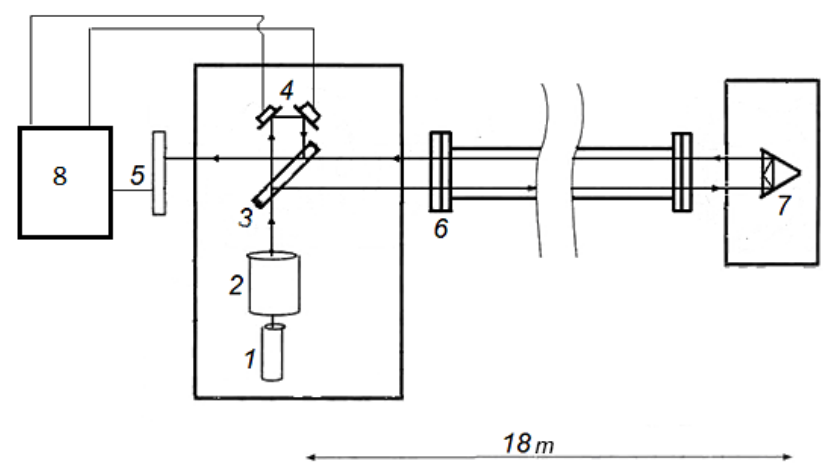

Figure 1. Scheme of a laser strainmeter-interferometer. $1-\mathrm{He}-\mathrm{Ne}$ laser, 2 - collimator, 3 - flat-parallel plate, 4 - flat-parallel adjustment mirrors, 5 - photodiode, 6 - light guide, 7 - triple-prism reflector, 8 - registration system block.

tern bands. The capabilities of the interference method are limited by the accuracy of measurement of band shifts $\Delta N$, which is determined by the parameter of interference pattern sharpness $F_{k}$ and is characterized by the relation $F_{k}=\frac{\Delta \lambda}{\delta \lambda}$; i.e., it is the relation of the distance between maxima to the maximum half width $\delta \lambda$.

The advantage of a laser strainmeter against a mechanical one is the absence of a mechanically sensitive element (Agnew and Wyatt, 2003; Amoruso and Crescentini, 2009; Dolgikh et al., 2012). The effect of meteorological parameter variations on the instrument is mainly the change in the laser beam optical path. When a sealed or vacuum-treated light guide is used, the measurement accuracy of the Earth crust relative deformations for the best interferometer models is $10^{-10}-10^{-11}$. Some restrictions, determined by the effect of meteorological parameter variation, are imposed on registration accuracy for the measurements carried out by "open"-type strainmeters without light guides. Wind, precipitation, air temperature and pressure have the most significant impact (Dolgikh et al., 2012). A special cover may be used to eliminate wind and precipitation effects. Air pressure and temperature change is a slow process that lasts for several hours. It will be shown furthermore that during the investigation of deformations in connection with geoacoustic emissions, faster processes that last up to several minutes are considered. Thus, during the analysis of such short effects, air pressure and temperature changes may not be taken into account. In terms of calculation data, a strainmeter installed under such conditions has a relative deformation measurement accuracy of not less than $10^{-8}$. Results of the experiments in Kamchatka show that for the deformations of such an order and more, some effects appear in sedimentary rocks when acoustic signals are generated in the frequency range from hundreds of hertz to the first tens of kilohertz (Dolgikh et al., 2007).

A laser strainmeter-interferometer was installed on the ground surface on case pipes of two $5 \mathrm{~m}$ dry wells $18 \mathrm{~m}$ 


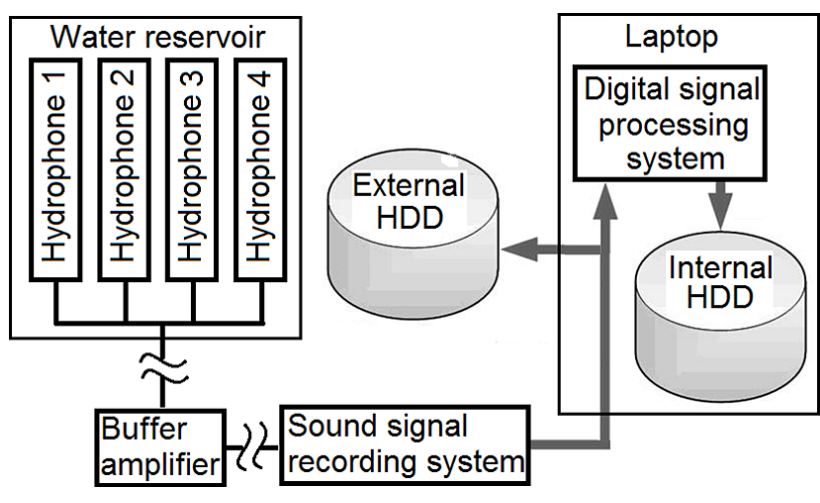

Figure 2. Structural scheme of the geoacoustic emission registration system.

spaced (interferometer measurement arm length) at the Karymshina complex geophysical observation site in Kamchatka. Figure 1 shows its structural scheme, where 1 is the frequency-stabilized $\mathrm{He}-\mathrm{Ne}$ laser with the frequency instability of $2^{-9}$ for a day. The light guide was used at the stage of adjustment and testing of strainmeter operation. In the result of the first year of measurements, it was refused and changed to a special cover from precipitation and wind. It is due to the fact that for most of the year (from November till June), there is much snow (the height is more than $2 \mathrm{~m}$ ) in the region of the observations. The snow is like a thermos, stabilizing the temperature and additionally protecting the system from wind and precipitation. The strainmeter readings were thoroughly examined for the possible effect of meteorological parameters on minute and hourly intervals. In the case of detection of such an effect, the data were removed from further processing.

The system for geoacoustic emission measurement was realized by directed broadband piezoceramic hydrophones installed in covered artificial reservoirs with the size $1 \times 1 \times$ $1 \mathrm{~m}^{3}$ (Kuptsov, 2005; Smirnov and Marapulets, 2012). The distances between the hydrophones of 5 to $50 \mathrm{~m}$ were chosen according to the estimation of acoustic signal attenuation in the frequency range from hundreds of hertz to the first tens of kilohertz where the maximum of geoacoustic radiation is registered. The receiving system included four hydrophones oriented downward, with the diameter of the receiving plate $D=65 \mathrm{~mm}$ and the length of the directional diagram $\theta=\lambda / D$, where $\lambda$ is the radiation wavelength. The structural scheme of the geoacoustic emission registration system is illustrated in Fig. 2. Continuous registration of a signal in the sound range was carried out simultaneously with digital filtration of the signal in the ranges $0.1-10$, 30-60, 70-200, 200-600, 600-2000, 2000-6500, and 6500$11000 \mathrm{~Hz}$, with the detection and the following collection at a second interval (Marapulets et al., 2012). The meteorological parameters (especially wind and rain) affected the recorded signal in the range up to $100 \mathrm{~Hz}$ the most, but they did not disturb the observations of geoacoustic emissions at higher frequencies. Anthropogenic noise (airplanes, cars and diesel generator) caused disturbances that were rather simply detected during data interpretation. To analyze the seismic state, an online catalogue of the Kamchatka branch of the RAS Geophysical Service was used.

At a distance of $15 \mathrm{~m}$ from the measuring systems, a Conrad WS-2103 digital weather station was installed. It measured air pressure, temperature, relative humidity, wind speed and rain intensity every $10 \mathrm{~min}$. Wind speed measurements were carried out at the height of $4 \mathrm{~m}$ from the ground surface, whereas other parameters were measured at the height of $2.5 \mathrm{~m}$.

\section{Main results and discussion}

Registration of near-surface sedimentary rock deformations has been carried out since 2007. An example of the data is presented in Fig. 3. Rock relative deformation $\varepsilon$ was considered (Fig. 3a). In order to analyze its dynamics, first differences were applied. They were calculated by averaged close values of $\varepsilon$ at a second interval. They were considered as estimations of rock deformation rate $\dot{\varepsilon}$ (Fig. 3b).

In the course of the investigation of geoacoustic emissions, it was determined that anomalies in the kilohertz frequency range register 1-3 days before strong earthquakes at distances of the first hundreds of kilometers from an epicenter (Kuptsov et al., 2005). As an example, Fig. 4 illustrates a nearly 1 day anomaly that was observed on 22-23 August 2006 before a group of 15 seismic events registered on 24 August 2006 at a distance of about $200 \mathrm{~km}$. The strongest earthquake with magnitude $M=6.5$ occurred at 21:50 UTC on 24 August 2006 at an epicentral distance of $190 \mathrm{~km}$. The earthquake hypocenter coordinates are $51.15^{\circ} \mathrm{N}, 157.54^{\circ} \mathrm{E}$; the depth is $43 \mathrm{~km}$. Hereafter, the earthquake data were taken from the base of the USGS National Earthquake Information Center (NEIC). In this case, an emission anomaly of a complicated form was registered, in which, against the background of a continuous increase in acoustic noise level in kilohertz frequency ranges, higher-frequency quasi-periodic pulsations were observed. The statistics of the registered geoacoustic emission anomalies before earthquakes from 2002 to 2007 were estimated. It has been ascertained that more than $80 \%$ of earthquakes with magnitude $M>5$ at a distance of up to $300 \mathrm{~km}$ were preceded by geoacoustic emission anomalies 1-3 days before an earthquake, but after $54 \%$ of emission anomalies, no earthquakes were observed within 3 days. That means that more than half of geoacoustic emission anomalies were false ones from the point of view of earthquake precursors. The registration statistics for acoustic emission anomalies before earthquakes are presented in detail in the paper (Marapulets et al., 2012).

The relation of geoacoustic disturbances, preceding seismic events, to geodeformation changes was under investi- 


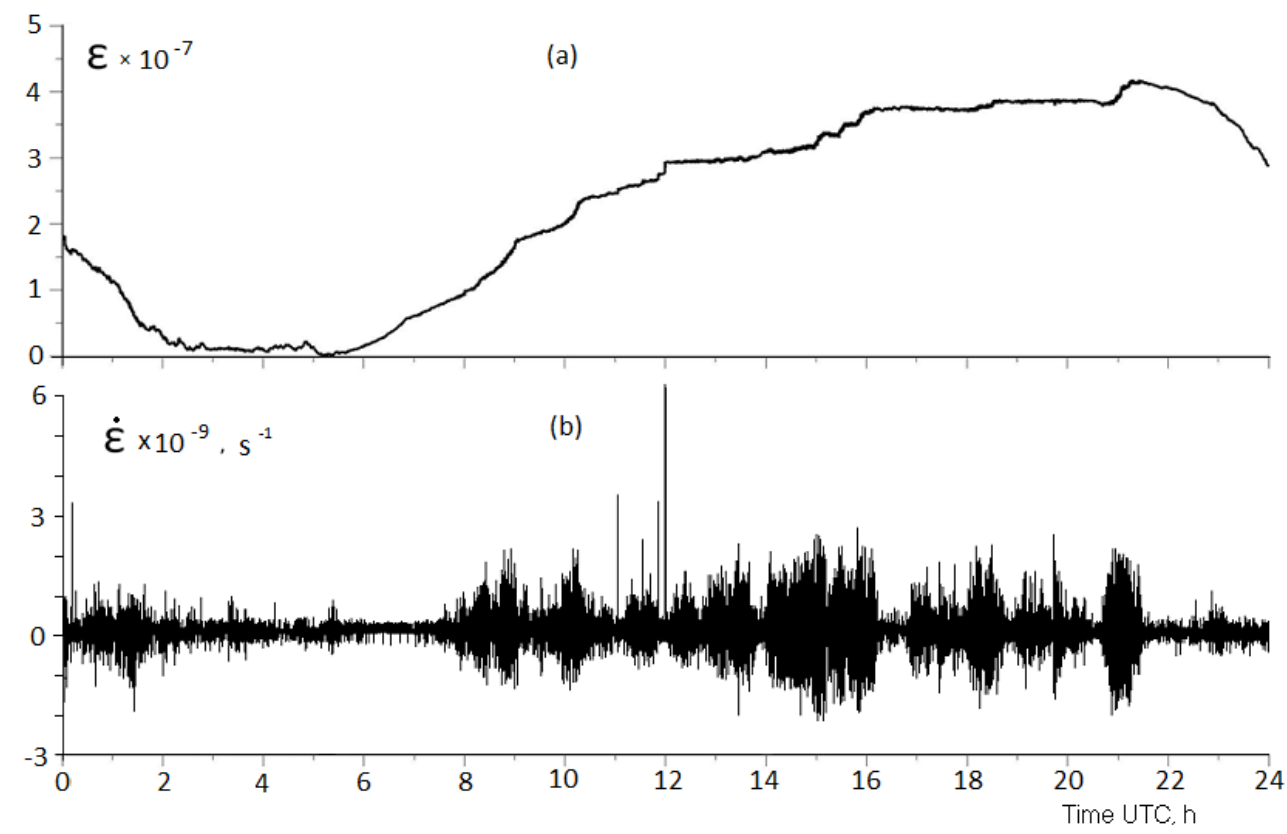

Figure 3. Relative deformation $\varepsilon$ (a) and its rate $\dot{\varepsilon}$ (b) on 9 October 2009 .

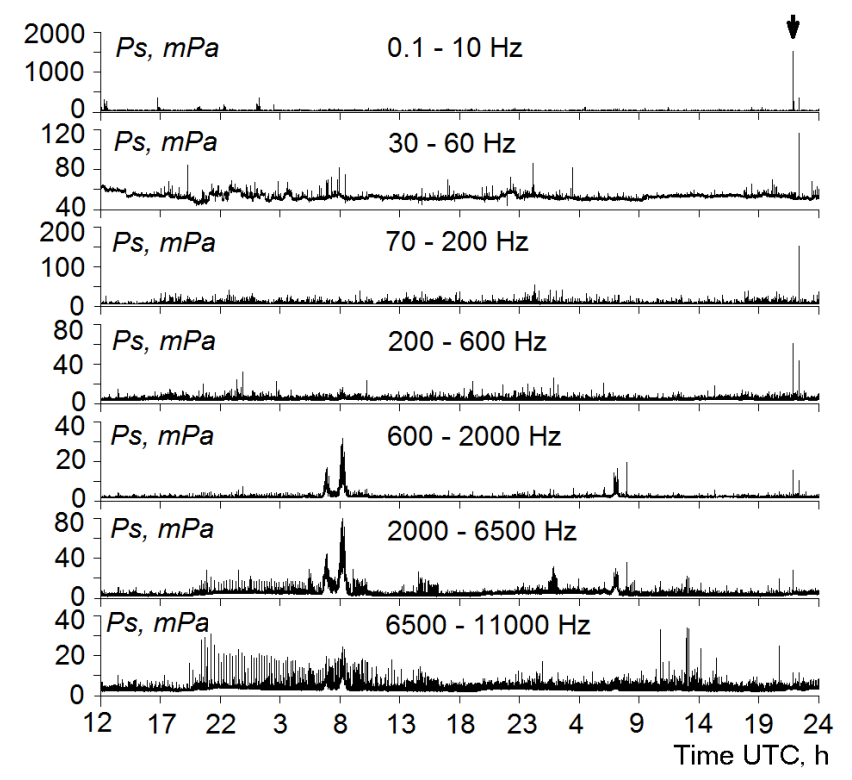

Figure 4. Acoustic emission plots in seven frequency ranges on 2224 August 2006. The arrow indicates the earthquake at 21:50 UTC.

gation. In order to do that, a piezoceramic hydrophone was temporally installed in a water reservoir on the strainmeter base. In the case experiment on 1 May 2007, an anomalous deformation pattern in comparison to the levels of calm diurnal variation was registered. These sharp oscillations had quite a large amplitude of about $10^{-8}$ relative to the diurnal values (Fig. 5a). Such behavior of relative deformation $\varepsilon$ lasted for about $8 \mathrm{~h}$ and took place $25 \mathrm{~h}$ before an earthquake

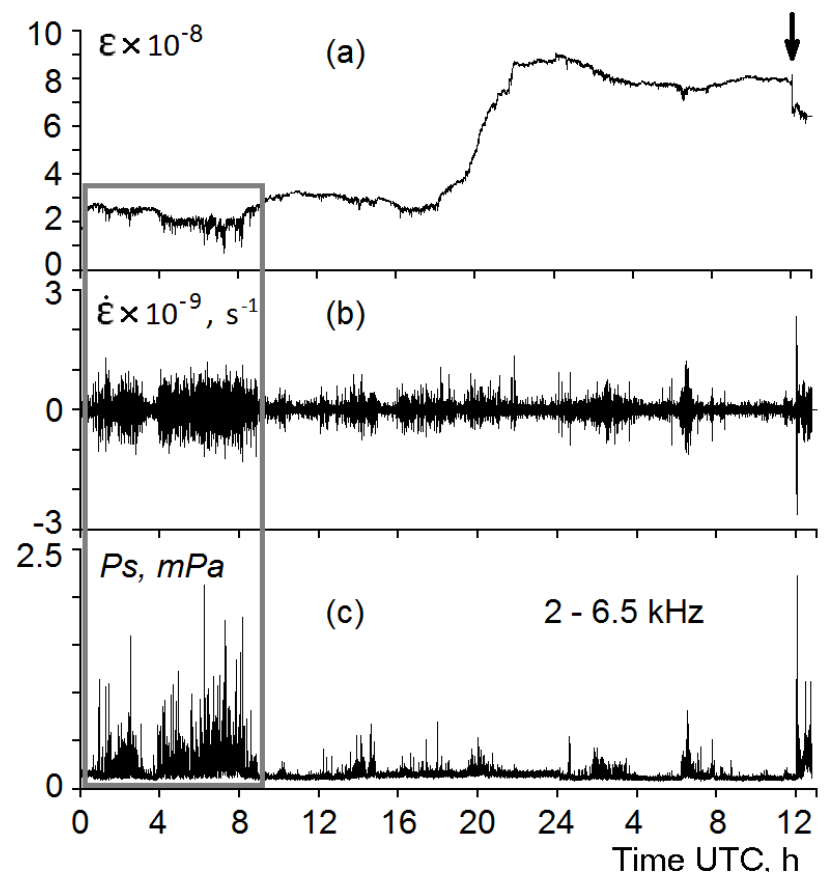

Figure 5. Graphs of relative deformation $\varepsilon$ (a), deformation rate $\dot{\varepsilon}$ (b), and acoustic pressure $P_{\mathrm{S}}$ (c) on 1-2 May 2007. The arrow indicates the earthquake.

with magnitude $M=4.9$, which occurred on 2 May 2007 at 12:00 UTC at the epicentral distance of $143 \mathrm{~km}$. Earthquake hypocenter coordinates are $52.41^{\circ} \mathrm{N}, 160.16^{\circ} \mathrm{E}$; the depth is $27 \mathrm{~km}$. Geoacoustic emission analysis for the same period discovered a sharp increase in acoustic pressure $P_{\mathrm{s}}$ collected 


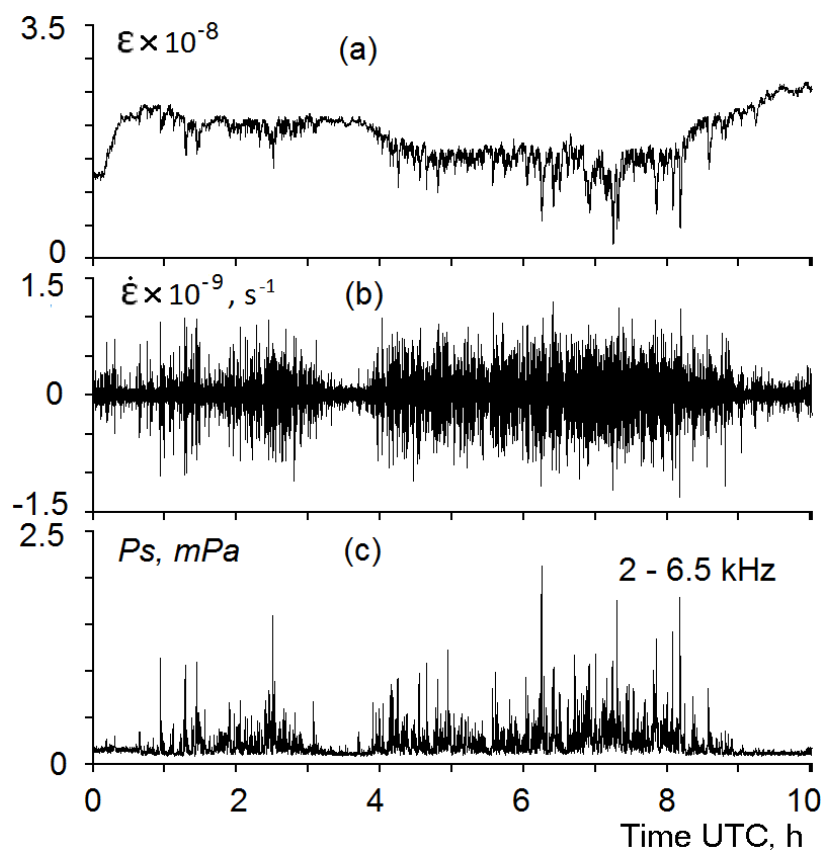

Figure 6. Graph of relative deformation $\varepsilon$ (a), its rate $\dot{\varepsilon}$ (b) and acoustic pressure $P_{\mathrm{S}}(\mathbf{c})$ on 1 May 2007.

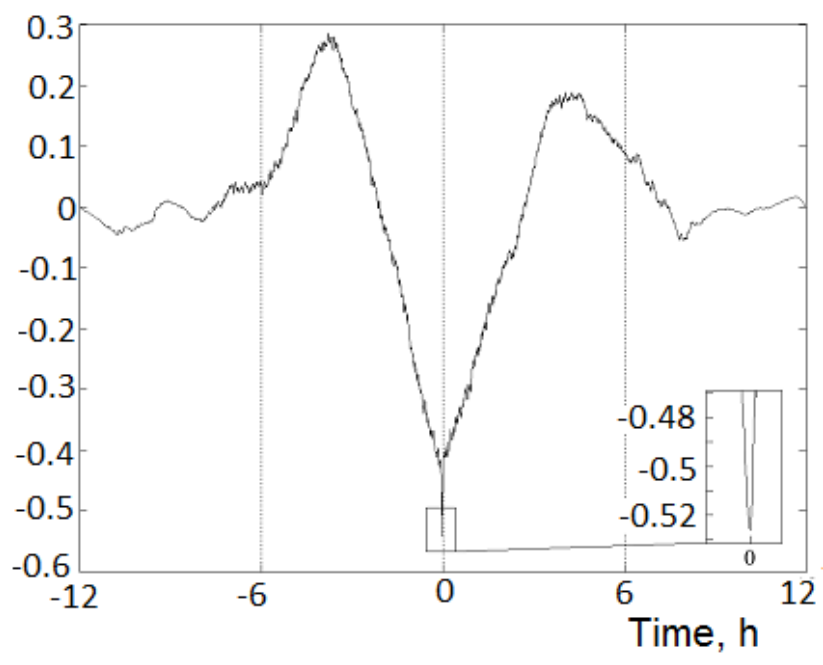

Figure 7. Cross-correlation function graphs between acoustic pressure $P_{\mathrm{S}}$ series in the range of $2.0-6.5 \mathrm{kHz}$ and rock deformations $\varepsilon$.

on the second interval, especially in the frequency range of $2.0-6.5 \mathrm{kHz}$. Anomalous increase in the emission amplitude corresponds to the region of sharp oscillations in the deformation (Fig. 5c), which is clearly seen on the graph of its rate (Fig. 5b). The area of disturbances is marked by a rectangle (Fig. 5) and is shown in Fig. 6 in detail.

To estimate the relation between geoacoustic emission and rock deformations, cross-correlation functions (CCF) between acoustic pressure second series $P_{\mathrm{S}}$ in the range of 2.0$6.5 \mathrm{kHz}$ and relative deformation $\varepsilon$ (Fig. 7), as well as the

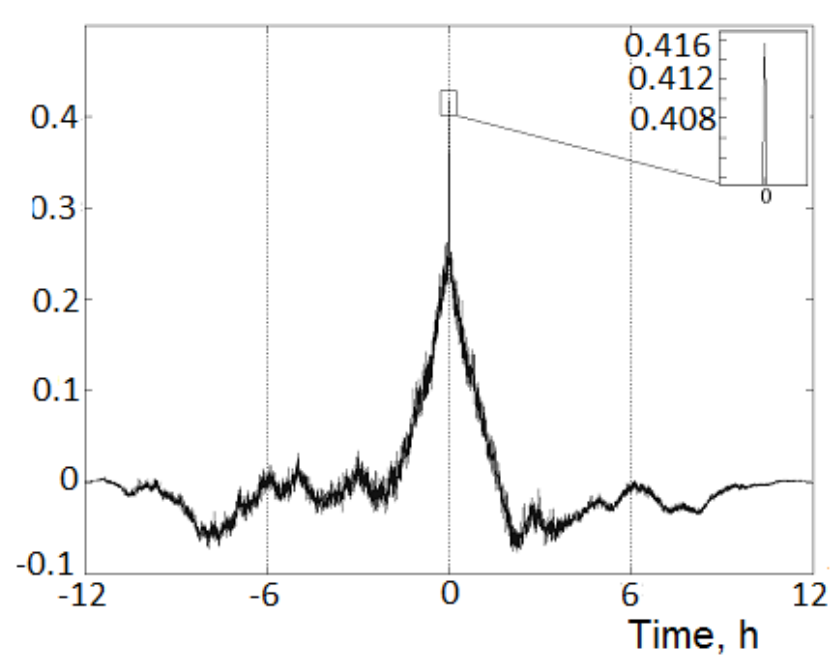

Figure 8. Cross-correlation function graphs between acoustic pressure $P_{\mathrm{S}}$ series in the range of $2.0-6.5 \mathrm{kHz}$ and rock deformation rate $\dot{\varepsilon}$.

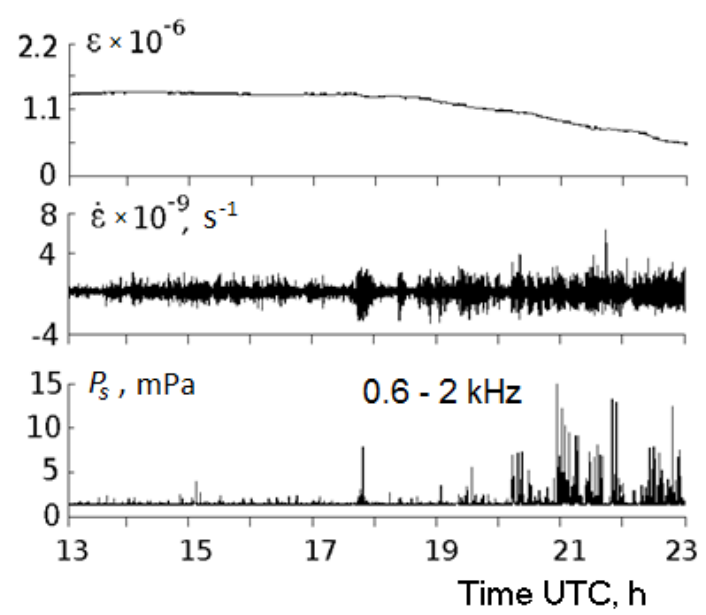

Figure 9. Examples of geoacoustic emission anomalies during nearsurface rock compression: rock relative deformation $\varepsilon$ (a), deformation rate $\dot{\varepsilon}(\mathbf{b})$, and acoustic pressure $P_{\mathrm{S}}(\mathbf{c})$.

deformation rate (Fig. 8) for the period from 00:00 till 12:00 on 1 May, were calculated. In both cases, the CCF maximum was observed on a zero sift, and was -0.53 and 0.42 , correspondingly, with the significance level in both cases not less than 0.001 .

Furthermore, the results of joint investigations of geoacoustic emission (the hydrophone is installed at a distance of $50 \mathrm{~m}$ from the strainmeter) and rock deformation confirmed that emission anomalies in the kilohertz frequency range are observed during a significant increase in the deformation rate, during both near-surface sedimentary rock compression (Fig. 9) and tension (Fig. 10).

It is clear from the comparison of the graphs of emission and the deformation rate that geoacoustic disturbances oc- 


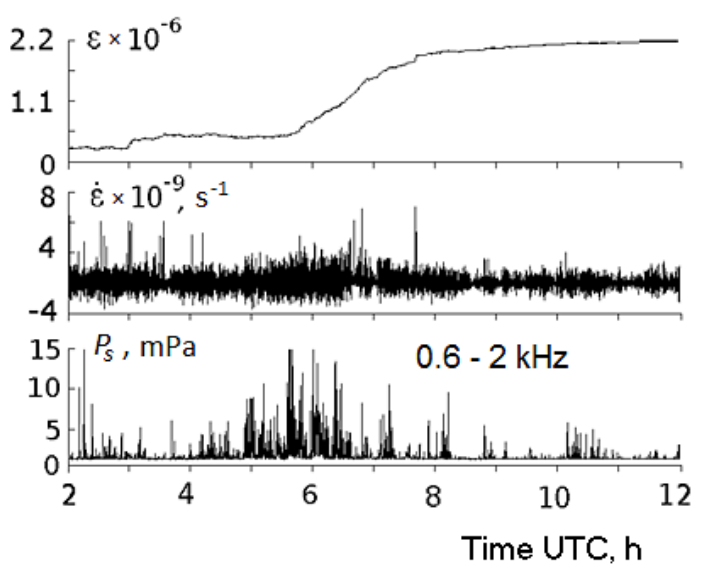

Figure 10. Examples of geoacoustic emission anomaly during nearsurface rock tension: rock relative deformation $\varepsilon$ (a), deformation rate $\dot{\varepsilon}(\mathbf{b})$, and acoustic pressure $P_{\mathrm{S}}(\mathbf{c})$.

cur during numerous sign-changing rock shifts of different amplitude. Relative deformations of some shifts are small enough; even at comparatively large amplitudes, they are not more than $10^{-8}$. The data, shown in Figs. 9 and 10, were obtained during seismically calm periods when no earthquakes with the energy class $K>10$ were registered at distances of up to $250 \mathrm{~km}$.

During the data analysis for the whole period of observations since 2007, diurnal data, when registration was stopped for different technical reasons, were removed from consideration. For this reason, during the first 2 years of the experiment, the period of adjustment of the measurement, it was impossible to obtain deformation long data series to estimate the annual scale pattern. During the following period, the number of gaps decreased significantly, and it allowed us to consider the geodeformation process behavior within long time periods.

Figure 11a shows an example of deformation change from March 2010 till February 2012. When constructing a graph, data gaps, which occurred as a result of the complex shutdown or detection of bad weather conditions, were replaced by median values. Due to considerable oscillations of deformations on the annual timescale, diurnal variations turned out to be smoothed. To make objective estimations, graphs of median values and the mean square deviation (MSD) of the difference between diurnal relative deformation maximal and minimal values $\Delta \varepsilon$, averaged in a week window, were calculated and plotted (Fig. 11b). Acoustic pressure pattern $P_{\mathrm{S}}$ in the range of $0.6-2 \mathrm{kHz}$, averaged in a day window, is illustrated in Fig. 11c. Due to the peculiarities of geoacoustic emission registration at the Karymshina site, this range is weakly influenced by meteorological factors, but the disturbances of the deformation nature affect it the most. Data averaging in a day window allowed us to eliminate short-term
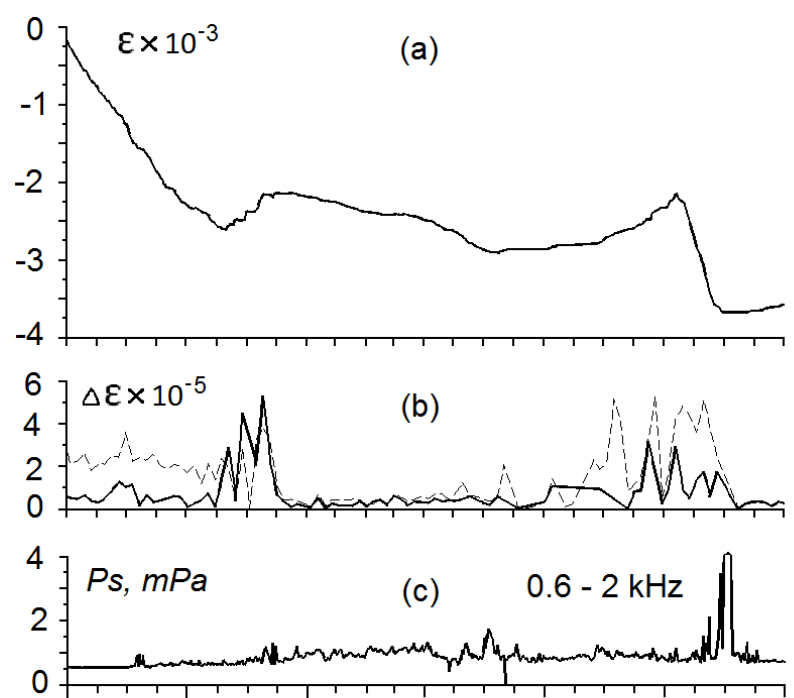

March July November March July November March

Time, months

Figure 11. Rock relative deformation $\varepsilon$ (a); median values (dashed line) MSD (solid line) of the difference between diurnal relative deformation maximum and minimum values $\Delta \varepsilon$, averaged in a week window (b); acoustic pressure $P_{\mathrm{S}}$ in the range of $0.6-2 \mathrm{kHz}$, averaged in a day window (c) from March 2010 till February 2012.

disturbances and to determine the specific level of acoustic pressure at long time intervals.

As follows from Fig. 11, a significant shift in the base line by a value of several centimeters occurred over the 2 years of registration, which seems to be erroneous. The authors think that the obtained results show a real change in the base line and are not determined by errors as long as the trend determined by hardware peculiarities of the registration system was removed during the data analysis. When a failure occurred in the strainmeter operation, or the meteorological parameters had a significant impact, the data were removed from consideration. The main reasons for the significant shift in the base line are the following. Surface sedimentary rocks on the bank mountain slope of the Karymshina River are constantly in motion; it is a shear plastic flow, the velocity of which exceeds the velocities of regional plastic deformation in Kamchatka by several orders. The rocks on the steep slopes are always close to an almost critical, avalanche-prone state, so they are so sensitive to weak deformation disturbances that occur locally in close proximity and as a result of remote earthquake precursors. It should also be considered that the strainmeter is installed in the zone of differentrank tectonic faults. Their dynamics may cause significant changes in surface sedimentary rocks.

As follows from Fig. 11, during long periods, rock primary compression or tension is observed, but the most interesting regions are those where geodeformation direction change occurred. For example, in July-November 2010 in the deforma- 
tion process, the primary compression is changed by primary tension, and the median values and the MSD show an average value increase and a relatively average value peak in relative deformation diurnal variations. From October 2011 till February 2012, deformation direction change occurred, the rock primary compression rate grew sharply, as well as the intensity of relative deformation per day. During this period, the most significant amplitude disturbance of geoacoustic emission was determined. It should be noted that such a strong compression for a short enough time period was registered for the first time.

\section{Conclusions}

Primary rock compression or tension, which lasts for several months, is observed in the deformation process registered at the observation site in Kamchatka. Similar results were obtained in the paper (Agnew and Wyatt, 2003). It allows us to suggest that similar effects are typical for the local deformation process. Geoacoustic anomalies are mainly registered during deformation direction change when the deformation process rate increases.

When deformations become more active, geoacoustic emission anomalies are observed in the form of a sharp and long increase in the level in the frequency range from hundreds of hertz to the units of kilohertz. During these periods, the deformation rate grows, and rock slips appear that result in the generation of the emission of increased intensity. The most vivid such effects are observed at the final stage of earthquake preparation. This result agrees well with the results of mathematical models (Alekseev et al., 2001; Dobrovolsky, 2000; Okada, 1985; Vodinchar et al., 2007) and natural experiments (Agnew and Wyatt, 2003; Berardino et al., 2002; Dolgikh et al., 2007; Sasorova et al., 2008). These authors showed that amplification of a deformation process occurs during earthquake preparation in the regions of their epicenters at distances of up to several hundreds of kilometers. Thus, anomalies of geoacoustic emission in the frequency range from hundreds of hertz to the units of hertz may be considered operative precursors of strong earthquakes.

Acknowledgements. The authors are very grateful to G. P. Gregori and H. I. Koulakov for their attention to the article and constructive discussion that helped to improve the manuscript.

Edited by: H. I. Koulakov

\section{References}

Agnew, D. C. and Wyatt, F. K.: Long-base laser strainmeters: A review. Scripps institution of oceanography technical report, http: //repositories.cdlib.org/sio/techreport/2, 2003.

Alekseev, A. S., Belonosov, A. S., and Petrenko, V. E.: A concept of multidisciplinary earthquake prediction using an integrated precursor, Vychislitel'naya Seysmologiya, 32, 81-97, 2001.

Amoruso, A. and Crescentini, L.: The geodetic laser interferometers at Gran Sasso, Italy: Recent modifications and correction for local effects, J. Geodyn., 48, 120-125, 2009.

Berardino, P., Fornaro, G., Lanari, R., and Sansosti, E.: A new algorithm for surface deformation monitoring based on small baseline differential SAR interferograms, IEEE T. Geosci. Remote Sens., 40, 2375-2383, 2002.

Dobrovolsky, I. P.: Theory of the earthquake preparation, UIPE RAS, Moscow, 2000.

Dolgikh, G. I., Shvets, V. A., Chupin, V. A., Yakovenko, S. V., Kuptsov, A. V., Larionov, I. A., Marapulets, Yu. V., Shevtsov, B. M., and Shirokov, O. P.: Deformation and acoustic precursors ofearthquakes, Dokl. Earth Sci., 413, 281-285, 2007.

Dolgikh, S. G., Chupin, V. A., Shvets, V. A., and Yakovenko, S. V.: Gornotaezhnoe geophysical system, Instrum. Exp. Tech., 55 , 298-299, 2012.

Gregori, G. P., Paparo, G., Poscolieri, M., and Zanini, A.: Acoustic emission and released seismic energy, Nat. Hazards Earth Syst. Sci., 5, 777-782, doi:10.5194/nhess-5-777-2005, 2005.

Gregori, G. P., Poscolieri, M., Paparo, G., De Simone, S., Rafanelli, C., and Ventrice, G.: "Storms of crustal stress" and AE earthquake precursors, Nat. Hazards Earth Syst. Sci., 10, 319-337, doi:10.5194/nhess-10-319-2010, 2010.

Kuptsov, A. V.: Changes of acoustic emission character corresponding to the final stage of seismic event development, Earth Physics, 10, 825-831, 2005.

Kuptsov, A. V., Larionov, I. A., and Shevtsov, B. M.: Peculiarities of geoacoustic emission during Kamchatka earthquake preparation, Volcanol. Seismol., 5, 45-59, 2005.

Levin, B. V., Sasorova, E. V., Borisov, S. A., and Borisov, A. S.: Estimating the Parameters of Small Earthquakes and Their Signals, J. Volcanol. Seismol., 3, 60-70, 2010.

Marapulets, Yu. V., Shevtsov, B. M., Larionov, I. A., Mishchenko, M. A., Shcherbina, A. O., and Solodchuk, A. A.: Geoacoustic emission response to deformation processes activation during earthquake preparation, Russ. J. Pac. Geol., 6, 457-464, 2012.

Morgunov, V. A., Luboshevskiy, M. N., Fabritsius, V. Z., and Fabritsius, Z. E.: Geoacousic precursor of Spitak earthquake, Volcanol. Seismol., 4, 104-106, 1991.

Okada, Y.: Surface deformation due to shear and tensile faults in a half-space, B. Seismol. Soc. Am., 75, 1135-1154, 1985.

Paparo, G., Gregori, G. P., Coppa, U., De Ritis, R., and Taloni, A.: Acoustic Emission (AE) as a diagnostic tool in geophysics, Ann. Geophys.-Italy, 45, 401-416, 2002.

Pollock, A. A.: Acoustic emission, Non-Destruct. Test., 209, 639642, 1970.

Pollock, A. A.: Acoustic emission inspection, Metals handbook, 17, 278-294, 1989.

Sasorova, E. V., Levin, B. W., and Morozov, V. E.: Hydroseismic-acoustical monitoring of submarine earthquakes preparation: observations and analysis, Adv. Geosci., 14, 99-104, doi:10.5194/adgeo-14-99-2008, 2008. 
Smirnov, S. E. and Marapulets, Y. V.: Influence of a single lightning discharge on the intensity of an air electric field and acoustic emission of near-surface rocks, Solid Earth, 3, 307-311, doi:10.5194/se-3-307-2012, 2012.
Vodinchar, G. M., Perezhogin, A. S., Sagitova, R. N., and Shevtsov, B. M.: Simulation of geoacoustic emission zones, Mathematical Models and Computer Simulations, 19, 59-63, 2007. 